Journal of Research of the National Bureau of Standards

Volume 90, Number 4, July-August 1985

\title{
A Density Comparison of Silicon Artifacts Between NML (Australia) and NBS (U.S.)
}

\author{
J. B. Patterson \\ National Measurement Laboratory, P. O. Box 218 Lindfield, NSW 2070, Australia \\ and \\ R. S. Davis \\ National Bureau of Standards, Gaithersburg, MD 20899
}

Accepted: June 6, 1985

\begin{abstract}
The densities of four silicon artifacts were measured in SI units to $1 \times 10^{-6}$ by NML (Australia) and NBS (U.S.). Agreement is within the experimental uncertainty of each laboratory. Two of the artifacts had been used in the determination of the Avogadro constant at NBS. The remaining two objects had been used at NBS to establish silicon density artifacts available as a Standard Reference Material (SRM).
\end{abstract}

Key words: density standards; hydrostatic weighing; international comparison; SI; silicon; volume standards.

\section{Introduction}

In order to compare density as measured in SI units at NML (Australia) and NBS (U.S.), four silicon transfer standards were measured in each laboratory.

The density scale at NBS is based on interferometric measurements of the diameters of four steel spheres. These measurements were terminated more than 10 years ago, but, at the time of the volume determination, density information was transferred to four singlecrystal silicon objects by means of hydrostatic weighing

About the Authors: The National Measurement Laboratory to which J.B. Patterson belongs is part of the Commonwealth Scientific and Industrial Research Organization in Australia. R. S. Davis serves with the Length and Mass Division in the NBS Center for Basic Standards.
$[1] .{ }^{1}$ NBS believes the density of these objects to be constant with time.

At NML, the volume of a hollow sphere of ultra-low expansion glass was measured interferometrically [2]. The sphere diameter was measured at various temperatures ranging from $6{ }^{\circ} \mathrm{C}$ to $40^{\circ} \mathrm{C}$, and the volume was calculated to fit a quadratic expression in temperature.

Both NBS and NML assign an uncertainty to their density or volume standards of approximately $1 \times 10^{-6}$ $(1 \mathrm{ppm})$ if the uncertainties are computed following BIPM recommendations [3].

In the first series of weighings, completed in 1980, two silicon crystals of approximately $100 \mathrm{~g}$ each were measured by NBS and NML. These crystals had been used at NBS in the determination of the Avogadro constant [4]. Their measured density at NBS and history

\footnotetext{
${ }^{1}$ Figures in brackets indicate literature references.
} 
prior to measurement by NML are given in [4], where the objects are referred to as $\mathrm{D}_{1}$ and $\mathrm{D}_{2}{ }^{2}$

The second series of measurements, completed in 1983, involved comparing density measurements of two silicon crystals, each having a mass nominally equal to $200 \mathrm{~g}$. The fabrication as well as the density determination of these objects at NBS are described in [5], where the objects are designated 703 and $806^{\prime}$. The objects were used to establish a stock of silicon artifacts of certified density. These are made available by NBS as a Standard Reference Material (SRM).

\section{Discussion}

\section{A. First Set}

The first set of measurements was undertaken informally. The motivation was simply to ascertain whether uncertainty arising from systematic behavior, which had been discovered but could not be explained [4], had been properly estimated by NBS. The unexplained behavior involved interferometric measurements of ball diameters that took on two different values depending on which of two cleaning methods had been used.

The results of the density comparison are summarized in table 1 . The total uncertainty assigned by NBS is 1.0

Table 1. Interlaboratory differences.

\begin{tabular}{ccccc}
\hline & & \multicolumn{2}{c}{ Density $\left(\mathrm{g} / \mathrm{cm}^{3}\right)$} \\
\cline { 3 - 5 } Crystal & Temp & NBS & NML & Difference \\
No. & $\left({ }^{\circ} \mathrm{C}\right)$ & & & \\
\hline $\mathrm{D}_{1}$ & 20 & 2.3290836 & 2.3290824 & $-0.0000012(0.52 \mathrm{ppm})$ \\
$\mathrm{D}_{2}$ & 20 & 2.3290825 & 2.3290825 & $0.0000000(0.00 \mathrm{ppm})$ \\
\hline
\end{tabular}

ppm for each crystal (see table 2A). Of this $0.8 \mathrm{ppm}$ is due to systematic behavior involving the cleaning of the steel balls. Thus, if this systematic behavior were understood, the NBS uncertainty could be lowered to about $0.6 \mathrm{ppm}$.

The uncertainties in the NML measurement are shown in table $2 \mathrm{~B}$. The uncertainty in sphere volume is a combination of the error associated with a quadratic fit to volume versus temperature $(0.93 \mathrm{ppm})$, phase correction $(0.3 \mathrm{ppm})$, and pressure correction $(0.6 \mathrm{ppm})$.

\section{B. Second Set}

Hydrostatic measurements at NBS were carried out using techniques which have been described well elsewhere [6]. The bath temperature was nominally $23.7^{\circ} \mathrm{C}$. The thermal coefficient of expansion of the silicon reference standards was assumed to be identical to that of 703 and $806^{\prime}$. Therefore, no temperature correction was applied even though the results are reported at $20^{\circ} \mathrm{C}$, the

\footnotetext{
${ }^{2}$ Note in [4] that densities in table $\mathrm{X}$ are given at $20^{\circ} \mathrm{C}$ but that densities in table $\mathrm{XI}$ are given at $25^{\circ} \mathrm{C}$.
}

temperature at which the density of the working standards is known.

No significant difference in density between 703 and $806^{\prime}$ could be discerned. The density of the two pieces taken together was, therefore, chosen as the datum to be compared with NML. Since the pieces are almost identical in mass and density, a simple average produces the same results as various weighting schemes which could have been used.

Data at NML were taken at three different nominal temperatures, as is shown in table 3 . The measurements at $20^{\circ} \mathrm{C}$ have a mean value of $2.3290708 \mathrm{~g} / \mathrm{cm}^{3}$ with a standard deviation of $0.43 \mathrm{ppm}$. These numbers, however, do not make use of the data taken at $4{ }^{\circ} \mathrm{C}$ and $10^{\circ} \mathrm{C}$. In order to take account of all the data available, a one-parameter fit was computed using accepted values for the thermal expansion of silicon [7]. The data of [7] were first fit to a cubic power series in the temperature region of interest. This result was then used to fit the data obtained by NML. The only adjustable parameter was the density of the silicon samples at $20^{\circ} \mathrm{C}$. Software developed at NBS proved very convenient for this analysis [8].

The result of the fit is that the density at $20^{\circ} \mathrm{C}$ is found to be $2.3290719 \mathrm{~g} / \mathrm{cm}^{3}$ with an approximate standard deviation of $0.33 \mathrm{ppm}$. This uncertainty must be expanded to $0.37 \mathrm{ppm}$, however, to take account of the effects of the reported uncertainty in the data of [7]. The total uncertainty is the root-sum-square of $0.37 \mathrm{ppm}$ and the first four items of table $2 B$.

Table 2A. Sources and NBS uncertainties.

\begin{tabular}{ll} 
Source & $\begin{array}{l}\text { NBS } \\
\text { Uncertainty [4] }\end{array}$ \\
Temperature of interferometer & $0.23 \mathrm{ppm}$ \\
Wavelength calibration & 0.08 \\
Phase shift in reflection & 0.12 \\
Photographic nonlinearity & 0.01 \\
Bath temperature & 0.03 \\
Mass of steel balls & 0.18 \\
Mass of silicon transfer crystals & 0.05 \\
Hydrostatic balance calibration & 0.27 \\
Cleaning uncertainty & 0.8 \\
$\quad$ Root-sum-square & $0.94 \mathrm{ppm}$ \\
Measurements involving $\mathrm{D}_{1}$ & 0.22 \\
Measurements involving $\mathrm{D}_{2}$ & \\
Total Uncertainty & $0.97 \mathrm{ppm}$ \\
\hline
\end{tabular}

Table 2B. Sources and NML uncertainties.

\begin{tabular}{ll}
\hline \hline & NML \\
Source & Uncertainty \\
Sphere volume measurement & $1.15 \mathrm{ppm}$ \\
Balance mass calibration & 0.05 \\
Sphere mass calibration & 0.17 \\
Silicon mass calibration & 0.43 \\
Hydrostatic weighing & 0.88 \\
\hline \multicolumn{1}{c}{ Root-sum-square } & $1.52 \mathrm{ppm}$ \\
\hline
\end{tabular}


Table 3. Mean densities in $\mathrm{g} / \mathrm{cm}^{3}$ of 703 and 806 as measured at NML.

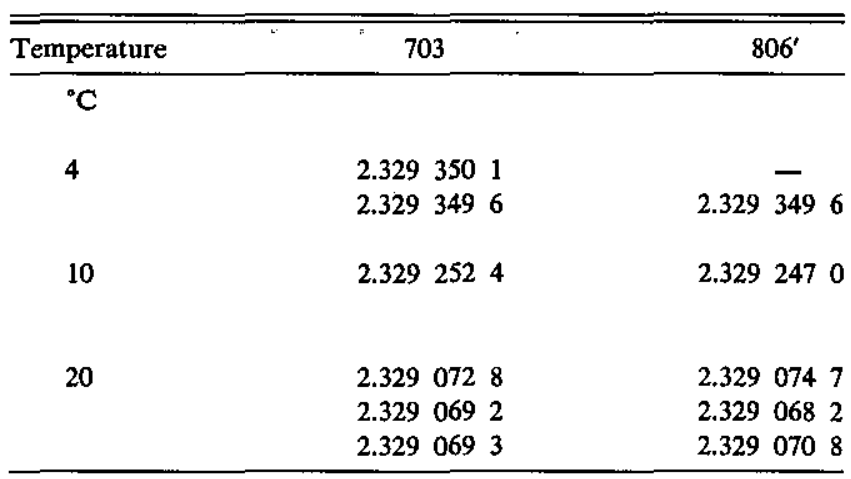

Comparisons between the two laboratories are shown in table 4. At NBS, the mass of the two artifacts was determined by substitution weighing with a 200 -g standard. The uncertainty represents the pooled standard deviation of 10 measurements. At NML, for reasons which are unclear, mass measurements of $806^{\prime}$ gave a slightly larger standard deviation than those of 703 . Nevertheless, agreement of the mass values and density values between the two laboratories is good.

As a result of these measurements, one can infer that densities assigned to silicon artifacts are consistent with the stated uncertainties at NML and NBS.

One of us (R. S. Davis) has recently reported on similar density comparisons with the Istituto di Metrologia "G. Colonetti" (IMGC) [9]. It is interesting to note that although the discrepancies with IMGC were also within expected uncertainties, the sign of the discrepancies is the same as was found with NML.

Table 4. Summary of results.

\begin{tabular}{|c|c|c|c|}
\hline & NBS & NML & Difference \\
\hline $\begin{array}{r}\text { Mass of 703: } \\
806^{\prime}:\end{array}$ & $\begin{array}{l}206.57459 \mathrm{~g} \\
207.76914\end{array}$ & $\begin{array}{l}206.57465 \mathrm{~g} \\
207.76915\end{array}$ & $\begin{array}{l}60 \mu \mathrm{g}(0.29 \mathrm{ppm}) \\
10 \mu \mathrm{g}(0.05 \mathrm{ppm})\end{array}$ \\
\hline $\begin{array}{r}\text { Uncertainty : } 703 \\
806^{\prime}\end{array}$ & $50 \mu \mathrm{g}(0.24 \mathrm{ppm})$ & $\begin{array}{l}58 \mu \mathrm{g}(0.28 \mathrm{ppm}) \\
89 \mu \mathrm{g}(0.43 \mathrm{ppm})\end{array}$ & \\
\hline $\begin{array}{l}\text { Density of } 703 \& \\
806^{\prime} \text { at } 20^{\circ} \mathrm{C} \text { : }\end{array}$ & $2.3290734 \mathrm{~g} / \mathrm{cm}^{3}$ & $2.3290719 \mathrm{~g} / \mathrm{cm}^{3}$ & $-1.5 \mu \mathrm{g} / \mathrm{cm}^{3}(0.64 \mathrm{ppm})$ \\
\hline Total Uncertainty: & $\begin{array}{c}2.6 \mu \mathrm{g} / \mathrm{cm}^{3} \\
(1.1 \mathrm{ppm})\end{array}$ & $\begin{array}{c}3.0 \mu \mathrm{g} / \mathrm{cm}^{3} \\
(1.3 \mathrm{ppm})\end{array}$ & \\
\hline
\end{tabular}

\section{References}

[1] Bowman, H. A.; R. M. Schoonover and C. L. Carroll. J. Res. Natl. Bur. Stand. (U.S.) 78A, 13-40 (1974).

[2] Bell, G. A., and J. B. Patterson. "Density standards-the density and thermal dilation of water" in Precision Measurement and Fundamental Constants II, B. N. Taylor and W. D. Phillips, eds., Natl. Bur. Stand. (U.S.) Spec. Publ. 617, 445-447 (1984).

[3] Giacomo, P., Metrologia, 17, 69-74 (1981).

[4] Deslattes, R. D., "Reference wavelengths, infra-red to gammarays, Avogadro's constant, mass and density" in Pro- ceedings of Course LXVIII Metrology and Fundamental Constants, Summer School of Physics-Enrico Fermi, Varenna, Italy (1976) 38-113 (Soc. Italiana di Fisica, Bologna (1980)).

[5] Davis, R. S., Metrologia, 18, 193-201 (1982).

[6] Bowman, H. A.; R. M. Schoonover and C. L. Carroll, Metrologia, 10, 117-121 (1974).

[7] Lyon, K. G.; G. L. Salinger, C. A. Swenson, and G. K. White. J. Appl. Phys. 48, 865-868 (1977).

[8] Filliben, J. J., Dataplot-introduction and overview, Natl. Bur. Stand. (U.S.) Spec. Publ. 667 (1984).

[9] Peuto, A., and R. S. Davis. J. Res. Natl. Bur. Stand. (U.S.) 90-3, 217-227 (1985). 